\title{
Social Media Use in Higher Education: A Review
}

\author{
Georgios Zachos *, Efrosyni-Alkisti Paraskevopoulou-Kollia and Ioannis Anagnostopoulos \\ Department of Computer Science and Biomedical Informatics, School of Sciences, University of Thessaly, \\ 35131 Lamia, Greece; frini@dib.uth.gr (E.-A.P.-K.); janag@uth.gr (I.A.) \\ * Correspondence: gzachos@sch.gr; Tel.: +30-223-102-8628
}

Received: 14 August 2018; Accepted: 1 November 2018; Published: 5 November 2018

\begin{abstract}
Nowadays, social networks incessantly influence the lives of young people. Apart from entertainment and informational purposes, social networks have penetrated many fields of educational practices and processes. This review tries to highlight the use of social networks in higher education, as well as points out some factors involved. Moreover, through a literature review of related articles, we aim at providing insights into social network influences with regard to (a) the learning processes (support, educational processes, communication and collaboration enhancement, academic performance) from the side of students and educators; (b) the users' personality profile and learning style; (c) the social networks as online learning platforms (LMS-learning management system); and (d) their use in higher education. The conclusions reveal positive impacts in all of the above dimensions, thus indicating that the wider future use of online social networks (OSNs) in higher education is quite promising. However, teachers and higher education institutions have not yet been highly activated towards faster online social networks' (OSN) exploitation in their activities.
\end{abstract}

Keywords: social media; social networks; higher education

\section{Introduction}

Within the last decade, online social networks (OSN) and their applications have penetrated our daily life. They have managed to transform young people's way of living while becoming one of the most important means of communication and entertainment [1-3].

Meanwhile, the educational community raises concerns that OSN are continuously decreasing students' interest for the educational processes, which is a problem that not only affects their performance, but sometimes also leads to dropouts [4-9]. The conventional education system seems to not respond effectively to the continuous decreasing of student interest [10], despite the several solutions that have been proposed so far [11,12].

In order to increase the awareness of students in the educational processes, blended entertainment and informational behavioral patterns have been proposed [13]. Social networks undoubtedly support such behavioral patterns and this seems to be an enjoyable and universally accepted medium in students' way of living [2,14,15].

Research efforts have been increased during the last decade so that successful aspects of social network use for educational activities could emerge. This review does not aim at answering specific research questions, nor it is a systematic effort to critically appraise or synthesize research studies. Thus, we do not employ a specific methodological method (e.g., Preferred Reporting Items for Systematic Reviews and Meta-Analyses [PRISMA]), but rather highlight relevant research and studies by presenting their results and highlighting related issues, problems, and challenges along with possible solutions. 


\section{Popular Social Networks and Higher Education}

Social media like Facebook, Twitter, Myspace, Google+, LinkedIn, Instagram, and so on are used daily by millions of people worldwide, especially young people. According to [16], in a sample consisting of 3000 students in USA, 90\% of them use Facebook, while 37\% use Twitter as a communication tool. Another study in this country shows that about $71 \%$ of higher education students are Facebook users [17].

Facebook is possibly the most popular among the social networks for personal and educational purposes [14,18-22]. Moreover, students use online social network (OSN) platforms daily from 10 to $60 \mathrm{~min}$ on average [23], even when studying [24]. Furthermore, academic institutions make use of social networks for internal management of educational issues [25-27].

In our study, we review studies that revealed the positive impact of OSNs and social networks on education processes, and mainly on higher education. We collected 77 articles that have been published from 2010 onwards, and we noticed that Facebook and Twitter are the basic OSN platforms for educational purposes. More specifically, in 55 articles (71.43\%), Facebook was either the only OSN involved or the basic one along with others; in 9 articles (11.699\%), Twitter appeared as the main educational tool; and a further 9 articles (11.69\%) involved other social networks like Myspace, Google+, LinkedIn, and others. The remaining 4 articles (5.19\%) involved all social networks with no exception.

All articles have been further classified into four distinct fields that aim to group the positive influence and involvement of social networks in (a) the learning processes (support, educational processes enhancing, communication and collaboration, academic performance) from the students' and instructors' viewpoint; (b) the user's personality and learning style (ways or methods to acquire knowledge, academic culture, effectiveness); (c) the social networks such as online learning platforms (LMS-learning management system); and (d) their institutional use (use of OSNs by faculty for management and educational purposes). These four fields are presented in more detail in the following paragraphs.

\section{Social Networks and Learning Processes}

During this decade, new ways to seek knowledge have emerged using social networks in both formal and informal learning.

Formal learning is defined as a hierarchically structured educational system organized in sequential time periods, from nursery, primary, and high school to university, including academic studies, specialized training, as well as vocational and technical learning programs for all ages [28,29]. According to the same authors [28], informal learning is considered as the learning process by which each person learns and acquires attitudes, values, knowledge, and skills directly from his/her daily experience and social environment. This is also called learning based on interaction [30] or lifelong learning [31].

Many studies show that students use OSNs mostly for socialization purposes, for exchanging views or ideas, and for entertainment purposes [14,32-35]. However, such kinds of activities can be incorporated into educational procedures [36]. Thus, while some studies [23,37] show that students use Facebook mainly in order to increase their communal presence, some others [27,38] claim that Facebook use affects students' education, either directly or indirectly. Also, in a related study conducted at Islamia University in Bahawalpur of Pakistan with more than 600 participated students, nearly $90 \%$ claimed that they are using Facebook for their academic activities too [39]. Furthermore, from 160 researchers in philosophy and social studies at the University of Delhi, $71.25 \%$ stated that they were using Facebook during their research into collaborative learning processes [40]. As far as Twitter is concerned, an experimental study conducted in the Pharmacology Department of Boston University revealed that more than $60 \%$ of the participating students use Twitter for increasing their professional awareness and academic profile [41]. 
However, all the above findings conflict with the results of some other studies [34,42], in which the positive effect of OSN platforms in educational processes is in question. Authors of [34] carried out an extensive literature review and found out that very few related works prove the positive impact of social networks on education. In those cases, when that happens, OSNs are mainly used for informal learning situations (questions to "friends" for help or for pointing out some difficult topics). Furthermore, the authors of this study emphasize the lack of relevant references and wonder whether OSNs may effectively be used as educational tools. Finally, the research proposed a usability framework so as to make social networks appropriate as educational tools, mainly by increasing the students' interest. In our research, we noticed that this lack of research seems to start to subside.

\subsection{On the Side of Students}

In the research findings so far, students seem to use OSNs in many ways during their studies to reinforce their educational activities and in attempts to increase their academic performance.

\subsubsection{Support}

Several studies [43-45] attempted to investigate the effectiveness of educational programs when run in Facebook-like environments, while others [46-48] claimed that the adjustment to the university culture was smoothly achieved. In study [21] (p. 205), the authors pointed out that the social interactions the students receive through social networks "help students feel more connected to the college, which may subsequently increase the likelihood that they will persist beyond their first year". The authors also consider Facebook as the most useful social network for supporting students in their educational activities.

In a survey conducted in Israel [25], more than 70 accounts on Facebook and Twitter were created by several universities in order to support educational processes. Thanks to this, a supportive network for informal learning was created and the results concerning knowledge diffusion were quite encouraging.

Furthermore, authors of [49] studied the influence of social networks on students at Griffith University in Australia in terms of self-esteem. They noticed an improved students' effectiveness in learning and thus stated that OSNs have become an important supportive tool for their learning processes. They concluded that "OSNs can support students to develop their learning to a deeper level" [49] (p. 1).

In another study [40], more than 160 researchers of philosophy and social studies in Delhi University in India claimed that they prefer using OSNs for their research purposes (as tools that can facilitate their research). Similar opinions were expressed by pharmacology students in Boston University [41]. They recognized Twitter as a tool capable of facilitating the growth of their own learning network, called PLN (personal learning network). According to study [41] (p. 464), a PLN is "a collection of resources that individuals use to increase their knowledge and engage in their own learning".

\subsubsection{Enhancing educational processes}

Several studies, such as [36], [38], or [50], claim that OSN create new perspectives in the process of acquiring knowledge. Mainly, social networking sites allow students to participate in formal (e.g., study of course material) and informal (e.g., look for useful information everywhere) learning conditions. Students can match with people with a similar way of thinking and exchange knowledge in an informal way (e.g., exchange of their educational experiences) for educational purposes [37,47,51]. For instance, first-year students can get all the necessary information they need about their faculty by just discussing with older ones, which will help them to get used to their new academic life. More specifically, the research of [36] pointed out that $20 \%$ of students in Germany exchange knowledge associated with their study through StudiVZ, the German equivalent of Facebook. The study mainly refers to first-year students who are looking for new friends to better organize their new lives. 
Similarly, Hussain [39] noticed that sharing learning experiences between students via OSNs is linked to developing the virtual community across the world. Lewis et al. [52] (p. 112) called them "collaborative knowledge building communities". In addition, another study that took place in USM (Universiti Sains Malaysia), revealed that 300 students consider Facebook as a valuable and important tool that could support and enhance their language skills in English [20].

In the research described in [53], 20 Australian lecturers from Management, Arts, Humanities Studies, Information Technology, and Health Services described educational processes in which students are asked to produce and distribute their work using social networks. The results revealed that allowing the transparency of students' work through social networks creates new perspectives in learning, but could also produce conflicts. Students' concerns about possible copying appeared. They felt unprotected when their work was being published online and were quite frightened about contributing "poor online conduct" from other students. However, authors concluded that we have to consider "students' views and to further interrogate the central issues that can challenge the effective use of social web technologies in higher education" [53] (p. 94).

However, Mohamad [54] suggests that each instance of Facebook involvement in the education process enhances student motivation and understanding.

\subsubsection{Academic Performance}

All the above mentioned studies highlight several positive issues for supporting and upgrading educational processes through social network use, in parallel with successful educational outcomes. They examine the areas the OSNs may affect (e.g., social learning, communication, academic culture, etc.) and support that social networks can create a more efficient educational environment and increase (or sometimes expect to increase) educational performance [55]. Fewer studies [56,57] have mentioned the positive influences on students' performance through the use of OSNs.

However, measurable academic outcomes appear to be missing from the bibliography. For instance, how long a student uses OSNs and what academic performance s/he gets thanks to that has not been recorded. Our review and personal experience in this field do not affirm documented conclusions such as the following: Students that use Facebook daily for their studies have to expect certain positive results in their exams, or, the vast majority of top students use OSNs for study purposes.

Yet, some studies have some reservations on the positive effects of social networking in higher education [53], while others present the negative effects on students' "academic performance" [1,58]. According to Paul et al. [58] (p. 2118), "academic performance is a function of attention span, time management skills, student characteristics and academic competence". More specifically, some authors [53] raise concerns about whether social acceptance feelings finally prevail [48] when students publish their work in OSNs, or about possible plagiarism or possible rejection of their views.

Furthermore, Paul et al. [58] revealed a statistically important negative influence between the students' academic performance and the time they spend on OSNs. Junco [59] seems to agree in part with this point as they claim that "time spent on Facebook was significantly negatively predictive of GPA for freshmen but not for other students" [59] (p. 18). Grade point average (GPA) is the only method used in the literature for the measurement of college outcomes and academic performance $[1,59,60]$. While Michikyan et al. [61] claimed that there is also the reverse relation; that is, academic performance could give estimates for Facebook activity level. Their research indicates that college students who may experience difficulties during their studies and may underperform (as indicated by lower GPA) use social networks to gain support. Michikyan et al. [61] also stated that user activity (on Facebook) is more important than the time s/he spends. However, no significant connection was recorded between Facebook time use and academic performance [61,62].

In accordance with the above, authors of [24] investigated distractions in students during their study, discovering that low performance (index GPA) is noted by using social networks for education purposes. To reduce distractions, they recommended small designed "technological breaks", in order to enhance students' concentration. 
On their part, students are keen on using social networks within their study hours [63], even if that is considered inefficient [64]. According to the results of study [63], students and lecturers use free (internet) access during working hours, not only for entertainment but also for communication, for exchanging views and knowledge, and to support teaching action. As derived from their work, the key is not making a decision to implement limited access on OSN sites, rather it is to find an effective way to benefit all involved stakeholders [63].

Finally, Paul et al. [58] underlined that even if students are fully convinced that OSNs enhance their educational opportunities, they still do not use OSNs willingly, but rather they expect instructors to do so.

\subsubsection{Communication and Collaboration}

As discussed above, there are conflicting points of view about OSNs and positive academic performance. From the other side, there is a greater consensus for their contribution in communication and collaboration among education providers.

Firstly, communication, using more traditional Information Computer Technology (ICT) ways (e.g., e-mail and instant messaging) or OSNs (modern way), seems to be independent to users' previous "technological adequacy" or digital literacy as it is called in bibliography. Digital literacy [65] is defined as the ease of use of electronic devices (smart phones, computers, etc.), as well as their profile [66]. However, only a few years before, it was presented that previous computer use to communicate with others seemed to help in more easily adopting new computer learning systems. Particularly, Cho et al. [67] claimed that students involved with OSNs appeared to have greater flexibility in the use of computer learning systems (computer supported collaborative learning-CSCL).

One way or another, the majority of research studies agree that social networks and OSN platforms enhance students' collaboration, in general [55,68-70]. In agreement with this point of view, another study [54] also presented several positive elements/characteristics as benefits of using social networks in e-learning environments, such as enhancing students' motivation and understanding or identifying methods of collaborative learning by applying the use of Facebook.

Moreover, Madhusudhan [40] proved that collaborative learning benefits from OSN use were confirmed by the answers provided by $71.25 \%$ among 160 students who participated in a study conducted in Delhi University in India. As an extra factor, nearly $90 \%$ of 600 students who were involved in a similar study conducted in Islamia University in Pakistan claimed that the use of Facebook is helpful enough for their academic activities, especially for exchanging information with colleagues from abroad [39].

Furthermore, LaRue's research [71] in the Nursing Department of Pittsburgh's University also outlined how social networks are of assistance to group-based learning [72]. Similar results came out in a study that took place in Australia with students who used OSNs in their empirical research [53]; they were excited and seemed to be sufficiently motivated about social learning conditions that they experienced.

Thompson and colleagues [73] emphasized that the social component of learning is just as important as the cognitive component, and these two elements should not be separated from each other while trying to learn. Additionally, students can act both autonomously and collaboratively. For this reason, Sánchez and colleagues [22] strongly recommended that educators should use social networks to achieve greater levels of co-operation and teamwork in educational activities.

\subsubsection{Synopsis}

In conclusion, students enjoy using OSNs in their educational processes. They usually have successful results, especially in communication and collaboration cases. It seems that they have acquired a new supportive tool, or maybe a new "friend" to help them with college life and their studies, although it is not yet clear that it also helps to improve their grades. 


\subsection{On the Side of Educators}

In Tess [13], it appeared that educators do not support social networking in educational procedures as strongly as do their students. Similar hesitations are mentioned in Greece; students are more receptive to the use of Facebook in education than their teachers, although they said it is more connected to entertainment and information [74]. Manca \& Ranieri [42] also agreed with this point of view. Similarly, in another study [69] (p. 8) conducted among teachers from five different countries (Canada, USA, South Africa, United Kingdom, and Australia), there were only a few who "would consider applying Facebook, as part of their teaching strategy"; although several studies that had already been published suggested methods of technological enrichment of educational action and encouraged educators to test them, promising very positive results [75,76]. Indicatively, Deng and Tavares [77] suggested to educators and software developers methods to promote their online courses and how such platforms for online courses (e.g., Moodle) can become more successful. In the same work, teachers are encouraged to take advantage of Facebook's "social nature" so as to improve communication and cooperation with their students, further aiming at students' participation in educational processes.

The research of Waycott and associates [53], as referred to previously, was an example of successful contribution of OSNs to co-operation. It is also a successful example of activating educators in the direction of exploiting OSNs in educational practice. Educators were enthused about positive results, despite the recorded concerns from students who were afraid of losing intellectual property rights or being subject to bad comments about their published work [53]. In addition, Hew [23] claims that when educators provide more information about their activities and followed academic processes, students' expectations about their trustworthiness are positively influenced and improved.

In general, OSNs seem to be another tool that teachers should invest in [22] so as to bring their students closer, aiming at encouraging them to make greater use of OSNs for educational purposes. This is something that will contribute to the improvement of their (students') educational experience, will reinforce their motivation for learning, will positively reform educational reality, and will "expand the learning process beyond the boundaries of a traditional classroom" [22] (p. 147). In addition, such a student-centered perspective can offer students an active role in the learning process [78], by producing a more flexible and creative learning environment [79].

Educators, on the other hand, as mentioned before, appear hesitant. Do they trust social networks or do they expect more concrete evidence for their successful contribution? Are they afraid of the new methods and the changes that it brings or do they prefer the safety of the 'traditional' process? In any case, they are "likely in an experimental stage of implementation as they look for alignment between course activities and the SNS (social networking sites) applications" [13] (p. A66). This, of course, is something that always happens when attempting to incorporate new technological tools into education and curriculum.

\section{Social Networks, Personality, and Learning Style}

Online social networks (OSNs) seem to affect and be affected by individual temperament and behavior. Several aspects have been noted about the ways in which they affect young people [23,40], as mentioned earlier. It is interesting, however, to observe students' behaviors that are positively or negatively related to the OSN. According to Skues et al. [33], "open" personalities use Facebook more and have more friends, mostly to share their various interests with others [80]. Also, young people who feel lonely have several friends on Facebook, attempting to fight this feeling [46].

In the same study, however, it was found that self-esteem, narcissism, and neuroticism did not seem to be sufficiently related to Facebook. In another study [81], however, it was mentioned that there is a robust association between increasing self-esteem and frequent use of Facebook. Also, 52.5\% of the students who participated in the study conducted by the University of Delhi in India said that one of the benefits of using Facebook in their research is the increase of self-esteem and feelings of satisfaction [40]. 
Meanwhile, in the overwhelming majority, young people use social networks in their personal lives, for entertainment, information, and so on. When it comes to more "serious" issues (e.g., educational processes), it does not seem certain that they would decide to use them. In a related study carried out in USA [82] concerning the collection of protest requests for the closure of a university, students chose more traditional ways to be informed. Instead of social networks, they chose to express their disagreement by writing or speaking to politicians or signing protest memos.

Another aspect of the possible positive contribution of social networks to students' lives is the apparent upgrading of their cognitive behavior. In a related study [83], it was found that regular Facebook users present better results in cognitive skills tests, which explore verbal skills, memory utilization, spelling, and so on. They are also more accurate in their statements and have smaller distraction intervals [84].

Omar et al. [85] presented these effects and indicated ways for the students to exploit OSNs for the benefit of improving their language expression skills, in order to be able to better indicate different meanings during their online communication. In addition, $\mathrm{Yu}$ and his colleagues [48] claimed that OSNs contribute to university culture, which, along with social acceptance, plays a prominent role in improving educational outcomes.

However, according to another research [86], the use of OSNs for social entertainment (online games, blogging, chatting, etc.) creates negative effects on text comprehension, while online search (online newspapers, dictionaries and encyclopedias, general search terms) positively affects reading efficiency.

Another research [60] proved that all Facebook actions have no negative impact on learning. For example, online chatting or online games may have a negative impact on curriculum-related activities, but responses in comments, facts presentation, and simple photo overview seem to have a positive impact on educational processes.

More interesting are the views [34] that integrate social networks into a new ("neomilleneal") learning style that incorporates all new means and methods of our technology characterized period. That style includes widespread use of multi-technology tools, multi-faceted search, and synthesis of knowledge, as well as active learning through real but also virtual/simulated situations.

In conclusion, it is not clear whether OSNs affect the personality of the students positively or negatively. It seems, however, that they often change their learning style in a way to fit in more in modern technological times.

\section{Social Networks as Learning Management/Support Systems}

Another aspect of social networking education is the support of course management systems (CMS) or learning management systems (LMS), as they are otherwise called. Some years ago, Cho and colleagues [67] found that students with previous experience in social networking communications were more likely to use computer learning systems (computer supported collaborative learning-CSCL). This enforced them to invent ways to enrich these systems with OSN features.

Roblyer et al. [68] studied the possibility of OSNs becoming a dynamic tool to support educational co-operation between students and faculty, and they highlighted suggestions for enhancing learning as a result of this combination. Previous research in this field [14], presented empirical research data [87-89], recording positive results from the use of Facebook as an LMS.

Increasingly, the research of Cuellar and associates [44] focused on ways to combine OSN and LMS in order to obtain positive learning outcomes. In particular, they proposed an environment with social network characteristics; this system could draw educational data from different LMSs and exploit their potential to increase learning resources and generate useful analyses for educators and learners.

A simpler approach was presented by Mohamad [54], according to which the use of social networks is integrated into an e-learning environment. In this research, positive results emerge, in terms of increasing learning interest and understanding teaching concepts. 
The bibliography demonstrates that there is also a lack of use of social networks as exclusive learning systems. A relevant study [71], in the field of Nursing, presented positive results. It marked the evolution of the teacher's role into director/coordinator and the students' (role) as producers and not just consumers of educational information. In this case, Facebook functioned as a CMS (computer management software) by which the professor provided her/his students with information and instructions. Students in turn, had to combine and use all these appropriately, in an active and exploratory effort to bring knowledge closer.

Finally, a very interesting study [90] not only confirmed the impact of social networks on computer learning systems (here, research deals with MOOC-massive online open university courses, on the Internet), but also claimed to be able to "predict" the particular OSN used by the user to enroll in a specific university thematic field.

\section{Social Networks and Educational Institutions}

The work described in Kravvaris et al. [90] stands as one among the few successful and large-scale examples of an educational institution's involvement in combining social networks with educational procedures. This is why the tendencies of utilizing social networks in organizational roles regarding the educational institution appear to be less dynamic. Studies have documented the languid attitude that faculties have towards integrating social networks into the organizational functioning of institutions or work in the classroom. They prefer more conventional ways, such as e-mail [68].

At the same time, there is an important difference in the notion of Facebook's educational utility; students have much higher expectations than their faculties. Educational institutions sometimes prohibit access to social networks during working hours, adopting views supporting that the use of OSNs has adverse effects on student performance [64].

However, in a study conducted at three private universities in Indonesia, $60 \%$ of participants replied that they use social networks during working hours not only for fun, but also for disseminating information. They establish communication channels that support educational activities, such as announcements, reprogramming of tasks, communication for exam questions, and so on [63]. The study concluded that it would be wiser for institutions to adopt OSNs by designing and establishing appropriate policies for their use within their premises, always taking into account users' behavior in these environments. In fact, this has been attempted in Israel's universities, which created 47 Facebook accounts and 26 Twitter accounts, to assist with transmitting educational information to students [25]. These accounts operated in parallel with the "real" functioning of the institution and were used to transfer knowledge by facilitating informal learning. Students kept these accounts active, as opposed to the usual account rejection rate that social networks show. This shows that these institutions' efforts were welcomed by the academic community in Israel, anticipating higher expectations in regard to the interaction between university institutions and social networks.

In conclusion, faculties, such as teachers, do not show similar enthusiasm as do their students for the use of OSNs in the educational process.

\section{Conclusions and Discussion}

During this research, we attempted to compare 77 articles, published from 2010 onwards. The first thing to notice is the great interest in the scientific and academic community for social networks' educational use. Also, even if a few years ago this particular scientific field was considered poor [34,91], we realized that this seems to be changing.

This research revealed that Facebook dominates in social networks, as well as some exploitation trends of social networking in educational events. Firstly, these trends are about learning with all kinds of contributions (e.g., support, upgrading of educational processes, co-operation, performance). Secondly, they are mostly dealing with users' learning style and personality, and less with organizational issues. 
The results of our research seem quite encouraging for the successful use of social networks in education. There was almost complete agreement on their positive contribution to the communication and cooperation of students for educational purposes. It seemed that most researchers accepted OSNs as a helpful educational tool. While research efforts (or we could say anticipation) are demonstrated, it has also been noticed that researchers are facing many difficulties in achieving detached empirical data on possible enhanced academic performance $[1,58]$. Some of them, in fact, raise objections to positive effects.

With regard to other parameters that support successful educational action, such as communication, co-operation, academic culture, almost all of the research converged on the positive impact of OSNs $[36,48]$.

Teachers seem to be unenthusiastic to engage social networks in educational processes, despite studies encourage them to do so [22]. Of course, this seems to delay research enrichment by more empirical data.

Some research also dealt with the potential influence OSNs have on students' personality and cognitive behavior; their conclusions are almost positive, but with some objections. They revealed some increase in self-esteem, greater social acceptance from other students, better memory management, and better results in cognitive language skills tests. The criticism is mainly based on the type of occurring activities on social networks, in a sense that they could not all be beneficial; chatting and online games do not seem to help, as opposed to searching for information, as well as reviewing and describing events.

A few studies unveiled, at least so far, social networks' relationships with online learning systems (CMS, LMS, MOOC, etc.). This is probably because these relationships are-in a sense-new in the related literature. However, the first results of their joint combination appear quite encouraging. It is reasonable, therefore, to expect more studies in the near future.

Also, the administrative and teaching staff appear to be quite hesitant about the contribution of social networks to internal institutional and educational processes. Furthermore, despite the positive opinions of students about exploitation of social networks-both institutionally and educationally-some studies do not seem to share this point of view. This may be because of teachers' restraint until all positive results are confirmed and recorded. Either way, it deprives research of enrichment with empirical evidence.

On one hand, our research seems to confirm the expectation for revealing empirical data that would record the connection of social networks with successful academic outcomes. On the other hand, it raises difficulty for educators to integrate OSNs into educational practices in a massively and constructively manner.

This, of course, may also be because of the lack of proposed, well-designed, and organized methodologies or practices, which integrate social networks in the educational community. We do believe that such kinds of research efforts will rise in the near future.

Author Contributions: Conceptualization, G.Z., E.-A.P.-K., and I.A.; Methodology, G.Z. and I.A.; Validation, G.Z., E.-A.P.-K., and I.A.; Investigation, G.Z.; Resources, G.Z. and E.-A.P.-K.; Data Curation, G.Z.; Writing-Original Draft Preparation, G.Z.; Writing-Review \& Editing, G.Z. and E.-A.P.-K.; Supervision, I.A.

Funding: This research received no external funding.

Acknowledgments: We would like to thank the anonymous reviewers as well as the handling editor for the valuable comments and suggestions that helped us to improve this work.

Conflicts of Interest: The authors declare no conflict of interest.

\section{References}

1. Kirschner, P.A.; Karpinski, A.C. Facebook and academic performance. Comput. Hum. Behav. 2010, 26, 1237-1245. [CrossRef]

2. Vasalou, A.; Joinson, A.N.; Courvoisier, D. Cultural differences, experience with social networks and the nature of 'true commitment' in Facebook. Int. J. Hum. Comput. Stud. 2010, 68, 719-728. [CrossRef] 
3. Ainin, S.; Naqshbandi, M.M.; Moghavvemi, S.; Jaafar, N.I. Facebook usage, socialization and academic performance. Comput. Educ. 2015, 83, 64-78. [CrossRef]

4. Tinto, V. Dropouts from higher education: A theoretical synthesis of recent research. Rev. Educ. Res. 1975, 45, 89-125. [CrossRef]

5. Tinto, V. Leaving CEGEP: Rethinking the Causes and Cures of Student Attrition; University of Chicago Press: Chicago, IL, USA, 1993.

6. Bean, J.P. Dropouts and Turnover: The Synthesis and Test of a Causal Model of Student Attrition; Springer Link: Research in Higher Education: Urdorf, Switzerland, 1980; Volume 12, Issue 2; pp. 155-187. Available online: https: / / doi.org/10.1007 /BF00976194 (accessed on 30 October 2018).

7. Blumenfeld, P.C.; Kempler, T.M.; Krajcik, J.S. Motivation and cognitive engagement in learning environments. In The Cambridge Handbook of the Learning Sciences; Sawyer, R.K., Ed.; Cambridge University Press: New York, NY, USA, 2006; pp. 475-488.

8. Fortin, L.; Marcotte, D.; Potvin, P.; Royer, É.; Joly, J. Typology of students at risk of dropping out of school: Description by personal, family and school factors. Eur. J. Psychol. Educ. 2006, 21, 363-383. [CrossRef]

9. Lee, V.E.M.; Burkam, D.T. Dropping Out of High School: The Role of School Organization and Structure. Am. Educ. Res. J. 2003, 40, 353-393. [CrossRef]

10. Rocca, K.A. Student participation in the college classroom: An extended multidisciplinary literature review. Commun. Educ. 2010, 59, 185-213. [CrossRef]

11. Fata-Hartley, C. Resisting rote: The importance of active learning for all course learning objectives. J. Coll. Sci. Teach. 2011, 40, 36-39.

12. Brophy, J. Toward a model of the value aspects of motivation in education: Developing appreciation for particular learning domains and activities. Educ. Psychol. 1999, 34, 75-85. [CrossRef]

13. Connolly, T.; Boyle, E.; MacArthur, E.; Boyle, J. A systematic literature review of empirical evidence on computer games and serious games. Comput. Educ. 2012, 59, 661-686. [CrossRef]

14. Tess, P. The role of social media in higher education classes (real and virtual)—A literature review. Comput. Hum. Behav. 2013, 29, A60-A68. [CrossRef]

15. Przepiorka, A.; Blachnio, A.; Díaz-Morale, F.J. Problematic Facebook use and procrastination. Comput. Hum. Behav. 2016, 65, 59-64. [CrossRef]

16. Dahlstrom, E.; De Boor, T.; Grunwald, P.; Vockley, M. ECAR: National Study of Undergraduate Students and Information Technology. Available online: https://library.educause.edu/resources/2011/10/ecar-nationalstudy-of-undergraduate-students-and-information-technology-2011-report (accessed on 30 October 2018).

17. Duggan, M.; Brenner, J. The Demographics of Social Media Users, 2012. Pew Research Center's Internet \& American Life Project. Available online: http:/ /www.pewinternet.org/2013/02/14/the-demographics-ofsocial-media-users-2012/ (accessed on 30 October 2018).

18. Hargittai, E. Whose space? Differences among users and non-users of social network sites. J. Comput. Mediat. Commun. 2007, 13, 276-297. [CrossRef]

19. Smith, S.; Caruso, J.B.; Katz, R. The ECAR Study of Undergraduate Students and Information Technology. Available online: https://library.educause.edu/resources/2009/10/the-ecar-study-of-undergraduatestudents-and-information-technology-2009 (accessed on 30 October 2018).

20. Kabilan, M.; Ahmad, N.; Abidin, M. Facebook: An online environment for learning of English in institutions of higher education. Internet High. Educ. 2010, 13, 179-187. [CrossRef]

21. Gray, R.; Vitak, J.; Easton, E.W.; Ellison, N. Examining social adjustment to college in the age of social media Factors influencing successful transitions and persistence. Comput. Educ. 2013, 67, 193-207. [CrossRef]

22. Sánchez, A.R.; Cortijo, V.; Javed, U. Students' perceptions of Facebook for academic purposes. Comput. Educ. 2014, 70, 138-149. [CrossRef]

23. Hew, F.K. Students' and teachers' use of Facebook. Comput. Hum. Behav. 2011, 27, 662-676. [CrossRef]

24. Rosen, L.; Carrier, M.L.; Cheever, N. Facebook and texting made me do it: Media-induced task-switching while studying. Comput. Hum. Behav. 2013, 29, 948-958. [CrossRef]

25. Forkosh-Baruch, A.; Hershkovitz, A. A case study of Israeli higher-education institutes sharing scholarly information with the community via social networks. Internet High. Educ. 2012, 15, 58-68. [CrossRef]

26. Sarapin, S.; Morris, P. Faculty and Facebook friending: Instructor-student online social communication from the professor's perspective. Internet High. Educ. 2015, 27, 14-23. [CrossRef] 
27. Sturgeon, C.M.; Walker, C. Faculty on Facebook: Confirm or Deny? Available online: http://www. cmsturgeon.com/itconf/facebook-report.pdf (accessed on 20 April 2018).

28. Jeffs, T.; Smith, M. Using Informal Education; Open University Press: Buckingham, UK, 1990.

29. Colley, H.; Hodkinson, P.; Malcolm, J. Non-Formal Learning: Mapping the Conceptual Terrain, a Consultation Report. Available online: http:/ / eprints.hud.ac.uk/id/eprint/13176/ (accessed on 30 October 2018).

30. Jarvis, P. Adult Learning in the Social Context; Croom Helm: London, UK, 1987.

31. Longworth, N. Lifelong Learning in Action-Transforming Education in the 21st Century; Kogan Page: London, UK, 2003.

32. Pempek, T.; Yermolayeva, Y.; Calvert, S. College students' social networking experiences on Facebook. J. Appl. Dev. Psychol. 2009, 30, 227-238. [CrossRef]

33. Skues, L.J.; Williams, B.; Wise, L. The effects of personality traits, self-esteem, loneliness, and narcissism on Facebook use among university students. Comput. Hum. Behav. 2012, 28, 2414-2419. [CrossRef]

34. Everson, M.; Gundlach, E.; Miller, J. Social media and the introductory statistics course. Comput. Hum. Behav. 2013, 29, A69-A81. [CrossRef]

35. Sharma, S.K.; Joshi, A.; Sharma, H. A multi-analytical approach to predict the Facebook usage in higher education. Comput. Hum. Behav. 2016, 55, 340-353. [CrossRef]

36. Wodzicki, K.; Schwämmlein, E.; Moskaliuk, J. “Actually, I Wanted to Learn”: Study—Related knowledge exchange on social networking sites. Internet High. Educ. 2012, 15, 9-14. [CrossRef]

37. Cheung, C.; Chiu, P.; Lee, M. Online social networks Why do students use facebook. Comput. Hum. Behav. 2011, 27, 1337-1343. [CrossRef]

38. Cooke, S. Social Teaching: Student Perspectives on the Inclusion of Social Media in Higher Education. Available online: http:/ /dx.doi.org/10.1007/s10639-015-9444-y (accessed on 30 October 2018).

39. Hussain, I. A Study to Evaluate the Social Media Trends among University Students. Procedia Soc. Behav. Sci. 2012, 64, 639-645. [CrossRef]

40. Madhusudhan, M. Use of social networking sites by research scholars of the University of Delhi: A study. Int. Inf. Libr. Rev. 2012, 44, 100-113. [CrossRef]

41. Camiel, D.L.; Goldman-Levine, J.; Kostka-Rokosz, M.; McCloskey, W. Twitter as a medium for pharmacy students personal learning network development. Curr. Pharm. Teach. Learn. 2014, 6, 463-470. [CrossRef]

42. Manca, S.; Ranieri, M. Facebook and the others. Potentials and obstacles of Social Media for teaching in higher education. Comput. Educ. 2016, 95, 216-230. [CrossRef]

43. Teng, C.; Lin, B. Applying Facebook as a Management Method for the Teaching Platform to Develop Product Design. Commun. Comput. Inf. Sci. 2013, 374, 397-401.

44. Cuellar, P.M.; Delgado, M.; Pegalajar, C.M. Improving learning management through semantic web and social networks. Expert Syst. Appl. 2011, 38, 4181-4189. [CrossRef]

45. Tuncay, T.; Uzunboylu, H.; Teker, T. Students evaluation of EDU 2.0: A case study. Procedia Soc. Behav. Sci. 2011, 28, 948-956. [CrossRef]

46. Ellison, N.; Steinfield, C.; Lampe, C. The Benefits of Facebook “Friends:" Social Capital and College Students' Use of Online Social Network Sites. 2007. Available online: http:/ / onlinelibrary.wiley.com/doi/10.1111/j. 1083-6101.2007.00367.x / full (accessed on 30 October 2018).

47. Madge, C.; Meek, J.; Wellens, J.; Hooley, T. Facebook, social integration and informal learning at university: It is more for socializing and talking to friends about work than for actually doing work. Learn. Med. Technol. 2009, 34, 141-155. [CrossRef]

48. Yu, A.; Tian, S.; Vogel, D.; Kwok, R. Can learning be virtually boosted? An investigation of online social networking impacts. Comput. Educ. 2010, 55, 1494-1503. [CrossRef]

49. Tower, M.; Latimer, S.; Hewitt, J. Social networking as a learning tool Nursing students' perception of efficacy. Nurse Educ. Today 2014, 34, 1012-1017. [CrossRef] [PubMed]

50. Manasijevic, D.; Zivkovic, D.; Arsic, S.; Milosevic, I. Exploring students' purposes of usage and educational usage of Facebook. Comput. Hum. Behav. 2016, 60, 441-450. [CrossRef]

51. Greenhow, C.; Robelia, B.; Hughes, J.E. Learning, teaching, and scholarship in a digital age: Web 2.0 and classroom research: What path should we take now? Educ. Res. 2009, 38, 246-259. [CrossRef]

52. Lewis, S.; Pea, R.; Rosen, J. Collaboration with Mobile Media-Shifting from 'Participation' to 'Co-Creation'. Available online: http://www.computer.org/csdl/proceedings/wmute/2010/3992/00/ index.html (accessed on 28 April 2018). 
53. Waycott, J.; Sheard, J.; Thompson, C.; Clerehan, R. Making students work visible on the social web: A blessing or a curse? Comput. Educ. 2013, 68, 86-95. [CrossRef]

54. Mohamad, R. The Effectiveness of Social Networking Applications in E-Learning. Available online: https: / / link.springer.com/chapter/10.1007/978-3-642-24772-9_12 (accessed on 30 October 2018).

55. Mazer, J.P.; Murphy, R.E.; Simonds, C.J. I'll see you on 'Facebook': The effects of computer-mediated teacher self-disclosure on student motivation, affective learning, and classroom climate. Commun. Educ. 2007, 56, 1-17. [CrossRef]

56. Lee, R.B.; Baring, R.; Sta Maria, M.; Reysen, S. Attitude towards technology, social media usage and grade-point average as predictors of global citizenship identification in Filipino University Students. Int. J. Psychol. 2017, 52, 213-219. [CrossRef] [PubMed]

57. Maqableh, M.; Rajab, L.; Quteshat, W.; Masa'deh, M.T.R.; Khatib, T.; Karajeh, H. The Impact of Social Media Networks Websites Usage on Students' Academic Performance. Commun. Netw. 2015, 7, 159-171. [CrossRef]

58. Paul, J.; Baker, H.; Cochran, J. Effect of online social networking on student academic performance. Comput. Hum. Behav. 2012, 28, 2117-2127. [CrossRef]

59. Junco, R. Student class standing, Facebook use, and academic performance. J. Appl. Dev. Psychol. 2015, 36, 18-29. [CrossRef]

60. Junco, R. The relationship between frequency of Facebook use, participation in Facebook activities, and student engagement. Comput. Educ. 2012, 58, 162-171. [CrossRef]

61. Michikyan, M.; Subrahmanyam, K.; Dennis, J. Facebook use and academic performance among college students-A mixed-methods study with a multi-ethnic sample. Comput. Hum. Behav. 2015, 45, 265-272. [CrossRef]

62. Pasek, J.; More, E.; Hargittai, E. Facebook and Academic Performance: Reconciling a Media Sensation with Data. Available online: http://journals.uic.edu/ojs/index.php/fm/article/view/2498/2181 (accessed on 6 June 2018).

63. Rosmala, F.; Rosmala, D. Study of Social Networking usage in Higher Education Environment. Procedia Soc. Behav. Sci. 2012, 67, 156-166.

64. Brooks, S. Does personal social media usage affect efficiency and well-being. Comput. Hum. Behav. 2015, 46, 26-37. [CrossRef]

65. Eshet-Alkalai, Y. Digital literacy: A conceptual framework for survival skills in the digital era. J. Educ. Multimed. Hypermed. 2004, 13, 93-106.

66. Vrocharidou, A.; Efthymiou, I. Computer mediated communication for social and academic purposes: Profiles of use and University students' gratifications. Comput. Educ. 2012, 58, 609-616. [CrossRef]

67. Cho, H.; Gay, G.; Davidson, B.; Ingraffea, A. Social networks, communication styles, and learning performance in a CSCL community. Comput. Educ. 2007, 49, 309-329. [CrossRef]

68. Roblyer, M.D.; McDaniel, M.; Webb, M.; Herman, J.; Witty, J. Findings on Facebook in higher education: A comparison of college faculty and student uses and perceptions of social networking sites. Internet High. Educ. 2010, 13, 134-140. [CrossRef]

69. Visagie, S.; de Villiers, C. The consideration of Facebook as an academic tool by ICT lecturers across five countries. In Proceedings of the SACLA conference (SACLA2010), University of Pretoria, Pretoria, South Africa, 7-9 June 2010.

70. Munoz, C.; Towner, T. Opening Facebook: How to Use Facebook in the College Classroom. Available online: https:/ / www.learntechlib.org/primary/p/31031/ (accessed on 30 October 2018).

71. LaRue, E. Using Facebook as course management software: A case study. Teach. Learn. Nurs. 2012, 7, 17-22. [CrossRef]

72. Haigh, G.V.; Schmidt, W. The learning of subject matter in teacher-centered and group-centered classes. J. Educ. Psychol. 1956, 47, 295-301. [CrossRef]

73. Thompson, C.; Gray, K.; Kim, H. How social are social media technologies (SMTs)? A linguistic analysis of university students' experiences of using SMTs for learning. Internet High. Educ. 2014, 21, 31-40. [CrossRef]

74. Tsoni, R.; Sypsas, A.; Pange, J. Students' perspectives about the educational dimension of the social network Facebook. In Proceedings of the 8th International Conference in Open \& Distance Learning, Athens, Greece, 7-8 November 2015. 
75. Peruta, A.; Shields, B.A. Social Media in Higher Education: Understanding How Colleges and Universities Use Facebook. Available online: http:/ / dx.doi.org/10.1080/08841241.2016.1212451 (accessed on 30 October 2018).

76. Khan, T.; Kend, M.; Robertson, S. Use of social media by university accounting students and its impact on learning outcomes. Acc. Educ. 2016, 25, 534-567. [CrossRef]

77. Deng, N.; Tavares, J.L. From Moodle to Facebook Exploring students' motivation and experiences in online communities Students' perceptions of Facebook for academic purposes. Comput. Educ. 2013, 68, 167-176. [CrossRef]

78. Meyers, C.; Jones, T.B. Promoting Active Learning. Strategies for the College Classroom; Wiley Jossey-Bass: Indianapolis, IN, USA, 1993.

79. Martell, C. Age of Creative Insecurity: Student-Centered Learning. Historical Paper 7. J. Educ. Libr. Inf. Sci. 2015, 56, n1.

80. Bonds-Raacke, J.; Raacke, J. MySpace and Facebook: Identifying dimensions of uses and gratification for friend networking sites. Individ. Differ. Res. 2010, 8, 27-33.

81. Gentile, B.; Twenge, J.; Freeman, E.; Campbell, K.W. The effect of social networking websites on positive self-views. Comput. Hum. Behav. 2012, 28, 1929-1933. [CrossRef]

82. Kelling, N.; Kelling, A.; Lennon, J. The tweets that killed a university: A case study investigating the use of traditional and social media in the closure of a state university. Comput. Hum. Behav. 2013, 29, 2656-2664. [CrossRef]

83. Alloway, P.T.; Horton, J.; Alloway, G.R.; Dawson, C. Social networking sites and cognitive abilities. Do they make you smarter? Comput. Educ. 2013, 63, 10-16. [CrossRef]

84. Alloway, P.T.; Alloway, G.R. The impact of engagement with social networking sites (SNSs) on cognitive skills. Comput. Hum. Behav. 2012, 28, 1748-1754. [CrossRef]

85. Omar, H.; Embi, A.M.; Yunus, M. Learners' use of communication strategies in an online discussion via Facebook. Procedia Soc. Behav. Sci. 2012, 64, 535-544. [CrossRef]

86. Lee, Y.; $\mathrm{Wu}, \mathrm{J}$. The indirect effects of online social entertainment and information seeking activities on reading literacy. Comput. Educ. 2013, 67, 168-177. [CrossRef]

87. Wang, Q.; Woo, H.; Quek, C.; Yang, Y.; Liu, M. Using the Facebook group as a learning management system: An exploratory study. Br. J. Educ. Technol. 2012, 43, 428-438. [CrossRef]

88. Schroeder, J.; Greenbowe, T. The Chemistry of Facebook: Using Social Networking to Create an Online Community for the Organic Chemistry Laboratory. Innovate J. Online Educ. 2009, 5, 3.

89. Eger, L. Facebook a Similar Learning Tool for University Students as LMS? Procedia Soc. Behav. Sci. 2015, 203, 233-238. [CrossRef]

90. Kravvaris, D.; Nanis, G.; Kermanidis, K. Studying Massive Open Online Courses: Recommendation in Social Media. Available online: https:/ / dl.acm.org/ citation.cfm?id=2491875\&dl=ACM\&coll=DL (accessed on 30 October 2018).

91. Said, H.M.; Tahir, L.M. Towards identification of students' holistic learning process through Facebook in higher education. Procedia Soc. Behav. Sci. 2013, 97, 307-313. [CrossRef]

(C) 2018 by the authors. Licensee MDPI, Basel, Switzerland. This article is an open access article distributed under the terms and conditions of the Creative Commons Attribution (CC BY) license (http:// creativecommons.org/licenses/by/4.0/). 